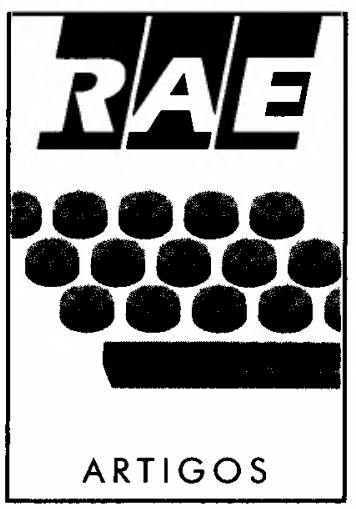

\title{
ADOTE CONSUMIDORES MAIS VELHOS NO MARKETING DAS ARTES
}

Diretrizes para duas questões complexas de marketing: marketing das artes e mercado de consumidores mais velhos.

Policies for two complex marketing questions: arts marketing and older consumers market.

PALAVRAS-CHAVE

Marketing, marketing cultural,

marketing das artes, estratégia

de marketing, consumidor.

\section{KEY WORDS:}

Marketing, cultural marketing.

arts marketing, marketing stra-

tegy, consumer.

*Professor de Marketing do Departamento deAdministraçăo da PUC do Rio de Janeiro. **Professor de Marketing da Graduate School of Management, University of Massachusetts. 
1. HIRSCHMAN, Elizabeth C. Aesthetics, ideologies and the limits of the marketing concept, Journal of Marketing, v. 47, n 3 , Summer, 1983, p. 45-5.

2. HOLBROOK, Morris B., ZIRLIN, Robert B. Artistic creation, artworks, and aesthetic appreciation: some philosophical contributions to nonprofit marketing, Advances in Nonprofit Marketing, v. 1, n. 1, 1985, p. 1-54

3. GOLD, Sonia. Consumer sovereignty and the performing arts. In: HENDON, Willian S., SHANAHAM, James L. Economics of cultural decisions, Cambridge, Massachusetts: Abt Books, 1983, p. 209-18.

4. SCHEWE, Charles D., HARLAN, E. Spotts Jr. Principles for communicating with aging health-care consumers, Clinical Laboratory Management Review, Sep./Oct. 1990, p. 21924.

5. DiMAGGIO, Paul J. Can culture survive the marketplace, Journal of Arts Management and Law, v, 13, 1983, p. 61-87. Revised in DiMAGGI0, Paul J., ed. Nonprofit Enterprise in the Arts, Studies in Mission and Constraints, New York, 0xford University, 1986, p. 65-92.

6. SEMENIK, Richard J. State of the art of arts marketing. Advances in Nonprofit Marketing, v. 2, 1987, p. 99-124.

7. HOLBROOK, Morris B. ZIRLIN, Robert B. Op. cit.

8. WOODS, Walter A. Classica aesthetics and arousal theory, Advances in Nonprofit Marketing, v.2, 1987, p. 203-39.
O mundo está envelhecendo. Isto é inevitável. Os resultados dos avanços tecnológicos têm gerado uma população cada vez mais idosa. A mudança para uma população mundial significativamente mais velha continuará a penetrar a demografia global e influenciará bastante a maneira pela qual as organizações de todos os tipos devem conduzir suas atividades de marketing. No Brasil, o grupo etário mais velho é o que mais cresce. Com base nos dados do IBGE (Instituto Brasileiro de Geografia e Estatística), o número de pessoas com mais de 60 anos cresceu neste século a uma taxa percentual mais de duas vezes superior à taxa de crescimento da população em geral. Entre 1960 e 1980, por exemplo, o crescimento da população brasileira foi de $70 \%$, enquanto que no grupo das pessoas com mais de 70 anos foi de $140 \%$. No ano 2000 , deverá existir um número maior de pessoas com mais de 50 anos do que de adolescentes! Muitos esforços de marketing que visaram aos consumidores mais velhos tiveram um sucesso surpreendente; no entanto, organizações do mundo das artes os têm negligenciado.

Estabelecer como alvo os mais velhos levanta duas questōes no marketing das artes: as dificuldades inerentes ao papel de consumidor no mundo artístico e a complexidade que o próprio processo de envelhecimento introduz no mercado definido por pessoas de mais idade.

\section{DIFICULDADES DO PAPEL DO CONSUMIDOR NO MARKETING DAS ARTES}

O mundo das artes concede aos consumidores um status menor do que o de "soberano" quando comparado a outras organizações de marketing, em decorrência de quatro forças interligadas. Em primeiro lugar, produtos de inspiração artística ${ }^{1}$ levam mais a uma orientação para o produto do que a uma orientação para o marketing, colocando os desejos e as necessidades dos consumidores abaixo daqueles dos produtores - os artistas ${ }^{2}$. Em segundo lugar - a natureza holística dos produtos de arte os tornam impróprios para uma decomposição analítica — uma demanda usual do marketing. Isto é, a satisfação derivada de uma obra de arte provém principalmente da impressão total e não da satisfação atribuída a características componenciais. Em terceiro lugar, a singularidade atribuída tanto à obra de arte quanto às respostas do consumidor dificulta a definição de cenários competitivos, complicando a capacidade do consumidor de fazer comparações significativas entre produtos artísticos antes da compra. E, por fim, a ambigüidade do papel do consumidor cria problemas, pois, apesar de constituírem alvos relevantes para o mundo das artes, os consumidores são por este criticados também pelos seus gostos, preferências e hostilidade em relação às inovações nas artes ${ }^{3}$.

\section{COMPLEXIDADE DEVIDO AO PROCESSO DE ENVELHECIMENTO DOS CONSUMIDORES MAIS VELHOS}

O envelhecimento envolve mudanças fisiológicas e psicológicas graduais. Ao longo do tempo, a maioria das pessoas fica com a visão e a audição prejudicadas, com a força reduzida e com menos flexibilidade muscular. $O$ envelhecimento afeta o desempenho psicológico à medida que a capacidade do sistema nervoso e a de processar informações falham e provocam mudanças cognitivas com maior impacto nas funções de memória e de percepção ${ }^{4}$. Em suma, o envelhecimento diminui as respostas aos estímulos visual e verbal.

Pode-se admitir como consumidores mais velhos pessoas com mais de 50 anos, o que constitui um marco crononológico inferior aos considerados pela gerontologia social e por outras áreas que se interessam pelo estudo de pessoas de mais idade. Por essa razão, bem como pelo acúmulo de experiência com a própria vida, essas pessoas trazem ao mercado manifestações distintas que as levam a constituir um grupo diferenciado e especial de consumidores.

\section{OBJETIVO}

Este artigo apresenta diretrizes que se referem às duas questões citadas. Embora sejam identificados progressos no marketing das artes tanto na prática ${ }^{5}$ quanto na pesquisa acadêmica ${ }^{6}$, a negligência na pesquisa com consumidores ${ }^{7}$ e o tratamento impróprio do elo entre a audiência e a oferta de marketing 8 sugerem que ain- 
da há muito a ser feito. Ter como alvo os consumidores mais velhos mostra relevância social e econômica, pois satisfazer suas necessidades alivia as pressóes da sociedade ${ }^{9}$, ajudando a retificar as injustiças de ações passadas, tanto de empresas, quanto de políticas sociais ${ }^{10}$. Os esforços empresariais, no sentido de compreender o segmento de pessoas de mais idade e fazerthes ofertas condizentes, revelam benefícios significantes ${ }^{11}$. É o que tem conseguido o grupo francês Club Med, que obtém cerca de $15 \%$ do total de sua receita de US\$ 1,4 bilhāo de pessoas com mais de 50 anos, procurando atraí-las ainda mais por meio de eventos artísticos de dança e teatro ${ }^{12}$. Nos EUA, pessoas com mais de 65 anos representam um mercado de US $\$ 130$ bilhôes e possuem a renda discricionária mais alta do que qualquer faixa etária ${ }^{13}$. $\mathrm{Na}$ Grā-Bretanha, pessoas acima de 50 anos possuem cerca de $75 \%$ da riqueza e gastam $21 \%$ a mais do que a média nacional. No Brasil, os consumidores acima de 50 anos possuem uma renda média superior à da população em geral. Estima-se que a renda global dessas pessoas esteja próxima dos $20 \%$ da renda nacional. E sua importância econômica só tende a aumentar, porque o número de pessoas alfabetizadas que ingressam diariamente nesse grupo é proporcionalmente maior do que o das pessoas que dele fazem parte. E esse é o tipo de renda que pode ser usado na compra de produtos do mundo das artes. Muitas atividades artísticas que hoje são deficitárias foram empreendimentos lucrativos há algumas décadas ${ }^{14}$, e o segmento dos mais velhos se apresenta como uma oportunidade para a inversáo dessa tendência.

\section{A NATUREZA DO MARKETING DAS ARTES}

A natureza do marketing das artes é especificada em um paradigma de três etapas proposto por Holbrook e Zirlin ${ }^{15}$ para uma comunicaçāo artística e estética. Primeiro, o artista cria uma entidade física ou conceitual; em seguida, o mundo das artes a classifica como uma obra de arte e, finalmente, o consumidor manifesta sua apreciação. Os proponentes enfatizam a natureza probabilística do elo entre as fases, afirmando que o mundo das artes pode não classificar determinado trabalho do

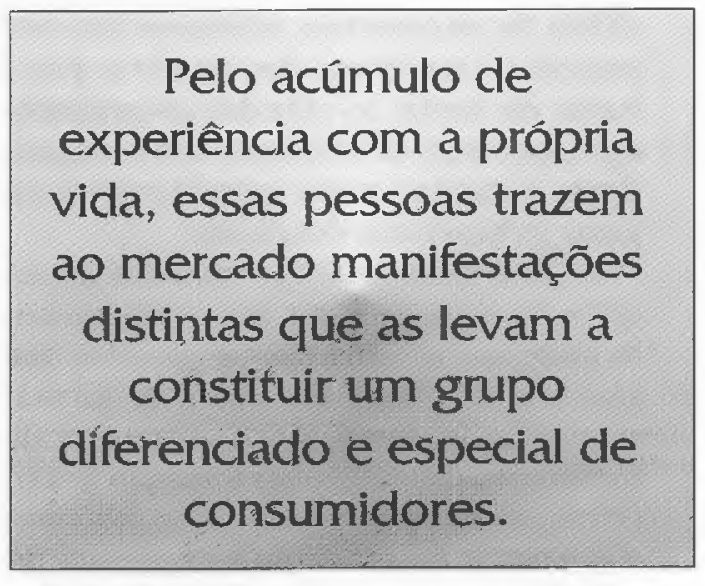

artista como obra de arte e, mesmo que isso seja feito, os consumidores podem não apreciar tal obra. O paradigma sustenta duas perspectivas direcionais. Na primeira perspectiva, o mundo das artes concede ao artista independência para a criatividade e desenvolvimento do produto; depois, ele o classifica como uma obra de arte; em seguida, busca os consumidores que provavelmente irão reagir da maneira mais positiva ao produto. $\mathrm{Na}$ terminologia de marketing, isto representa uma orientação para a venda ${ }^{16}$, nem sempre tida como recomendável. Na outra perspectiva, mais coerente com a filosofia de marketing, o mundo das artes primeiro identifica as atitudes e preferências do consumidor, depois as reúne num conceito de produto significativo, e, finalmente, transfere-o para os artistas, que deverāo produzi-lo. Isto reflete uma orientação na qual os desejos e necessidades do consumidor sustentam o mercado apropriado para a concepção do produto. Essa abordagem não viola a ordem das fases do paradigma, dado que nele se assume a independência das fases. Por essa razão, os artistas podem rejeitar as sugestóes ou propostas identificadas no público-alvo pelo mundo das artes.

Se as organizações de artes, pretendendo enfocar os consumidores mais velhos, favorecerem uma orientação voltada para a venda, elas devem direcionar seus esforços de marketing para mellhor se ajustarem às características desses consumidores, sem afetar a essência do conceito de seus produtos artísticos. Para isto, elas devem dar atenção especial aos seguintes fatores: segmentação demográfica, estratégia do produto aumentado e comunicação publi-
9. GELB, Betsy D. Discovering the $65+$ consumer. Business Horizons, May/June, p.42-6, 1982. In: SCHEWE, Charles D. The elderly market: selected readings, Chicago, Illinois: Introduction, 1985 .

10. SCHEWE, Charles $\mathrm{D}$. The elderly market... Op. Cit.

11. SCHEWE, Charles D. Digging deep to delight the older consumer, Working Paper, School of Management, University of Massachusetts, 1993.

12. Business Week, The old world gets older. Jan. 171994.

13. AGE WAVE, Inc. The shifting American marketplace. Emeryville, CA: Age Wave, 1989.

14. DiMAGgIO, Paul J. Op. cit.

15. HOLBROOK, Morris B., ZIRLIN, Robert B. Op. cit.

16. Idem, ibidem. 
17. SEMENIK, Richard J. Op. cit.

18. NATIONAL Research Center of the Arts, Americans and the arts, Study ne 831011, Louis Harris and Associates, 1984.

19. WOODS, Walter A. Op. cit.

20. LAZER, William. Dimensions of the mature market, Journal of Consumer Marketing, v. 3, n. 3, 1986, p. 2334.

21. STEINBERG, Margery, MACULIS, George, LLOYD, David. Benefit segmentation strategies for the performing arts. In: Bruce Walker et al. (eds.) An assessment of marketing thought \& practice. Educators' Proceedings, Chicago, Illinois: AMA, 1982. citária. Se, ao contrário, adotarem uma orientação de marketing, elas devem se preocupar em captar as atitudes, as preferências e os níveis de satisfação dos consumidores e usá-los como ingredientes para gerar os benefícios desejados.

$O$ restante deste artigo trata das conseqüências que o processo de envelhecimento pode causar à luz dessas questões que são identificadas da seguinte forma: segmentação demográfica, estratégia de produto aumentado, comunicação publicitária, identificação de atitudes, preferências e níveis de satisfação e uso desses resultados para criar os benefícios desejados. As três primeiras são relativas a uma orientação para venda e as outras duas, a uma orientação para o marketing. As diretrizes sugeridas em cada item refletem uma compreensão das mudanças relacionadas à idade, estudadas através de pesquisas conduzidas no campo das ciências biológicas e comportamentais.

\section{SEGMENTAÇÃO DEMOGRÁFICA}

A segmentação de mercado enfoca a descoberta de grupos homogêneos que reagem de maneira coerente com um dado esforço de marketing. Com base na demografia, ela aborda, principalmente, a idade, a renda, o sexo e a educação como variáveis-chave para subdividir o mercado. As características do processo de envelhecimento adicionam um significado extra à idade como base de segmentação e enfatizam a necessidade de ir além de seus marcos cronológicos.

Há associaçōes importantes entre fatores demográficos e a clientela das artes, como as que ligam o público das artes com os níveis mais elevados de educação e de renda, sendo o vínculo ainda mais forte se se considerar apenas o comparecimento a eventos artísticos ${ }^{17}$. A clientela das artes tende a estar nas primeiras ou nas últimas fases do ciclo de vida da família. Esses e outros fatores que serão apresentados adiante permitem propor as seguintes diretrizes.

Identificar associações entre a clientela mais velha e eventos específicos de artes

A vida cotidiana fornece inúmeros exemplos de gostos e atitudes que variam com a idade. $\mathrm{E}$, conseqüentemente, a seg- mentação de idade se apresenta como a mais típica no procedimento de subdivisão de mercado, uma vez que ela serve bem para identificar as principais preferências em grupos cujo acesso e substancialidade são mais facilmente definidos.

Uma pesquisa feita nos $\mathrm{EUA}^{18}$ mostra que o consumidor com mais de 50 anos possui uma freqüência anual média, em algumas apresentações de artes, maior do que os que estão na faixa etária dos 18-19 anos. Os valores mais elevados aparecem em três dos nove eventos de artes considerados: teatro, música clássica, ópera/ teatro musical. Valores mais baixos, porém próximos aos dos mais jovens aparecem em música popular, balé/dança moderna/ música folk e museus. O grupo mais jovem mostra valores expressivamente mais altos apenas em cinemas e em vídeos de eventos culturais. Por sua vez, outra fonte indica que o consumidor mais velho acha que ouvir música em casa, a forma mais popular de se "consumir arte", é somente um meio de relaxar ${ }^{19}$. Uma interpretação simples desses dados permite supor certas ligações entre a idade e as formas de arte preferidas, e sugere que os consumidores mais velhos preferem eventos "ao vivo" em vez de "enlatados".

\section{Identificar subsegmentos dentro do segmento de consumidores mais velhos}

Pessoas mais velhas constituem um grupo diversificado. Somente pela idade cronológica, eles foram classificados como Velhos Jovens (55-64), Velhos Intermediários (65-74), Idosos (75-84) e Muito Idosos (mais de 85), sendo que ainda exibem maiores diferenças dentro dessas categorias do que entre elas ${ }^{20}$. Por isso, a idade é insuficiente para subdividir os mais velhos, tornando-se necessário combiná-la com outras bases como renda, localização geográfica, sexo, educação e estilo de vida.

Steinberg et al..$^{21}$ encontraram diferenças etárias ao classificar o mercado das artes por benefícios, subdividindo o público das artes em três segmentos: os que buscam cultura, os que procuram diversão temporária e os que de fato desejam ter uma experiência estética. Subdividiram também os que não freqüentam eventos de artes em quatro segmentos: os que buscam segurança, os hedonistas, os pragmáticos e 
os orientados para os filhos. Eles listaram correlaçōes demográficas para cada segmento, mostrando que a idade é um importante fator de associaçāo. Moschis ${ }^{22}$, por sua vez, subdividiu os mais velhos em quatro segmentos gerais de consumidores: eremitas saudáveis, sociáveis doentes, reclusos frágeis, indulgentes saudáveis; cada qual requerendo uma abordagem diferente de marketing para se ajustar aos seus desejos e maneiras de levar a vida. Não sendo freqüentadores de eventos de artes, é provável que os eremitas saudáveis exijam uma abordagem pedagógica mais forte; os sociáveis doentes demandem eventos de arte que proporcionem experiências sociais significantes; os reclusos frágeis, à medida que estão socialmente isolados e à parte da sociedade, exijam medidas que acomodem suas necessidades de proteçāo física; os indulgentes saudáveis peçam uma abordagem de marketing pragmática ou hedônica.

\section{ESTRATÉGIA DE PRODUTO AUMENTADO}

A estratégia de produto aumentado propõe a adição de características à essência do produto para torná-lo mais significativo e atraente para o mercado. Quanto a isso, as organizações de artes podem agir de duas formas interligadas: pelo acréscimo de características que diferenciem a proposta estética implícita ${ }^{23}$ - a inclusāo, por exemplo, de fatores que apelam para o status social ou intelectual ou para a nostalgia - ou pelas operaçōes que adicionam valor, como as lojas de presentes e restaurantes em museus ${ }^{24}$. A pesar de aceitas pelo mundo das artes ${ }^{25}$ como fontes de renda desvinculadas do negócio, essas operaçōes năo devem subverter a principal atividade artística ${ }^{26}$, mas sim juntar-se a ela. Tendo em vista essas consideraçōes, sugerese as seguintes diretrizes.

\section{Colocar maior ênfase na oferta de} experiências, em vez de características físicas, ao aumentar o produto de arte

$O$ envelhecimento muda os antecedentes de satisfaçāo da posse de bens tangíveis para o partilhamento de experiências. Isso abrange experiências vivenciadas, como ir a shows de arte, eventos esportivos e viagens, preferidas pelas pessoas

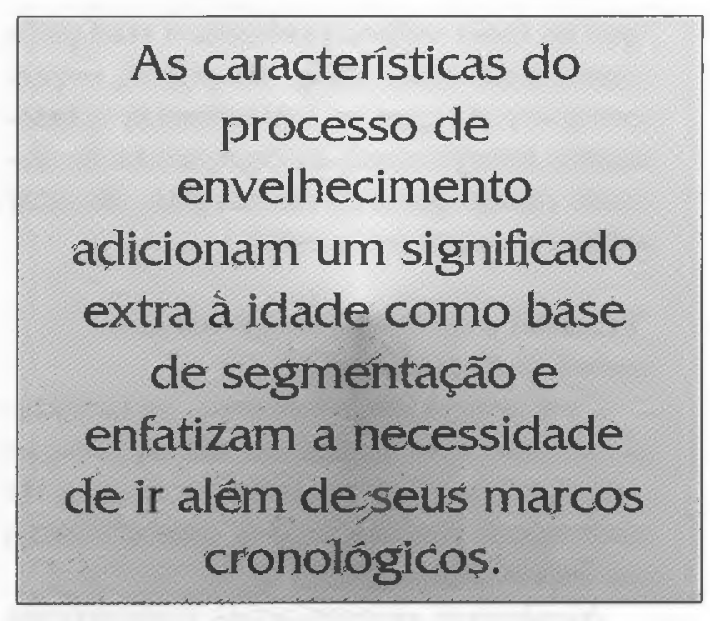

com menos de 60 anos, bem como "ser as próprias experiências", tais como as proporcionadas pelas relações interpessoais, introspecçāo filosófica e maior conexão com a vida, preferidas por pessoas com mais de 60 anos $^{27}$. Em suma, o consumidor de mais idade adota uma abordagem hedônica da vida ${ }^{28}$, que se reflete no maior consumo de serviços em vez de bens tangiveis.

Traduzindo essa conclusāo para a estratégia do produto aumentado, sugere-se a adição de características que envolvam ações mais do que características físicas, pois atividades para serem consumidas no local da arte realçam as experiências. Dessa maneira, a combinação de apresentações ao vivo com mostras em galerias de arte e museus pode ser mais eficaz em atrair consumidores mais velhos do que a adição de peças à exposiçāo.

\section{Realçar o papel interpessoal das oportunidades na adiçáo de experiências a um evento}

Pessoas mais velhas preferem eventos em que possam encontrar e interagir com outras pessoas, em vez de eventos cujo foco seja a simples contemplaçāo isolada. Melhor do que adicionar outras apresentaçōes de artes ao evento é aprofundar o valor pela introdução de oportunidades para a interação social.

$\mathrm{O}$ acréscimo de uma sessão para debates a um evento abre muitas oportunidades de interaçāo. Organizações de grupos para visitas a museus, galerias de artes e concertos também atingem esse objetivo. Algumas pessoas pensam, erroneamente,
22. MOSCHIS, George P. Marketing to older consumers, Westport, CT: Quorum Books, 1992.

23. WOODS, Walter A. Op. cit. KELLY, Robert F. Museums as status symbols II: attaining a state of having been. In: Advances in nonprofit marketing. $v$. 2, Greenwhich, CT: JAI Press, p.1-38.

24. LOVELOCK, Chistopher H., WEINBERG, Charles B. Retailing strategies for public and nonprofit arganizations, Journal of Retailing, v. $59, \mathrm{n}$. 3, Fall 1983, p. 93-115; NIELSON, Richard P. SMR Forum: strategic piggybacking - a self-subsidization strategy for nonprofit organizations. Sloan Management Review, v.23, p. 65-9.

25. DiMAgGI0, Paul J. Op. cit.

26. NIELSON, Richard, P. Op. cit.

27. SCHEWE, Charles D. Strategically positioning your way into the aging marketplace, Business Horizons, v. 34, ก. 3 , May-June 1991, p. 59-66.

28. LAZER, W. Op. cit. 
que os mais velhos preferem a tranqüilidade e o descanso longe dos outros, esquecendo-se de que as experiências e interaçōes interpessoais se equiparam ao elevado desejo que eles manifestam de estar onde outras pessoas estão.

\section{Vincular evidências tangíveis às} experiências adicionais

Conforme a idade aumenta, a capacidade de lidar com abstrações diminui, o que outorga aos itens tangíveis a funçāo de contrapeso para facilitar o entendimento e a lembrança.

Ao oferecer apresentaçōes, conferências ou debates, deve-se apoiá-las em aspectos tangiveis como slides, documentos impressos, folhetos, certificados e coisas do gênero. Um item para levar para casa, digno de ser mostrado devido à sua singularidade, qualidade ou significado, serve para

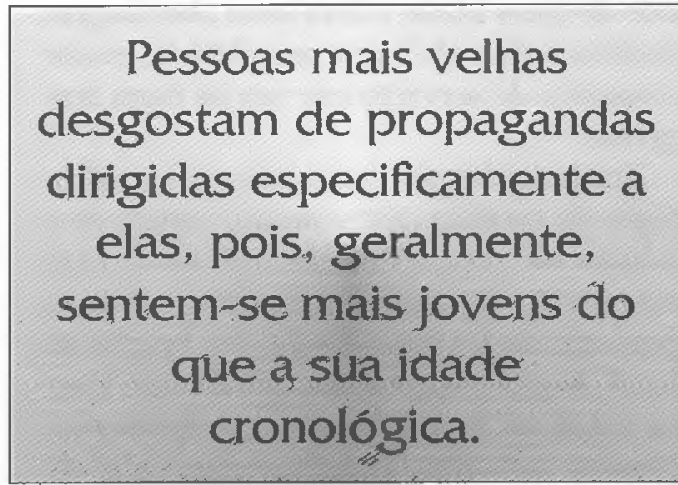

reforçar a memória e funciona como pretexto para conversas. Isto, por sua vez, pode desencadear uma cadeia de comunicaçāo verbal, criando fontes poderosas de promoçāo para futuros clientes. Todavia, itens desvinculados de uma experiência pouco servirāo a esse propósito.

Usar a estratégia de produto aumentado para acomodar dimensōes relacionadas ao uso do tempo dos consumidores

Embora tenham mais tempo disponivel do que os jovens, pessoas de idade requerem mais tempo para compreender um mesmo conjunto de informaçōes. Se, durante um evento, muita informação estiver para ser transmitida, como, por exemplo, num passeio pelo museu, atividades prévias poderāo ser úteis para reforçar a compreensāo e, conseqüentemente, o ní- vel de satisfação. Assim, uma breve visāo do museu e das suas peças poderia ser apresentada sob a forma de uma palestra antes do passeio de fato. Contudo, se nāo for possivel oferecer esse tipo de atividade, programas, brochuras e materiais audiovisuais poderiam estar disponíveis para os consumidores, algum tempo antes do evento. Desse modo, eles teriam a oportunidade de assimilar informaçōes, cada um no seu ritmo e da sua maneira.

Aumentar o produto de artes para se ajustar às limitaçôes físicas previstas

Como foi mencionado previamente, o envelhecimento provoca mudanças corporais e, com elas, as limitaçōes para uma plena apreciação de um evento artístico. E quando o prazer é reduzido, o interesse pelo evento diminui. Através da estratégia de produto aumentado, as organizaçöes de artes podem oferecer diversas compensaçōes para as limitações previsíveis. Por exemplo, deficiências de visāo e audiçāo podem ser contrabalançadas por uma localizaçāo conveniente, como assentos ou espaços reservados mais próximos do ponto focal do evento. Alguns freqüentadores podem ficar desanimados pela falta de disponibilidade de assentos confortáveis, especialmente em espetáculos longos, pois com a flexibilidade e a massa muscular reduzidas, podem achar desconfortável terem que ficar sentados por um longo período de tempo. Além disso, podem requerer mais intervalos, dado que muitos tomam remédios com freqüência; portanto, o comparecimento será mais atraente se facilidades adequadas, tais como bebedouros e banheiros limpos, estiverem disponíveis. Várias pesquisas apontam para o medo constante das pessoas de idade de se sentirem cansadas, sendo esta uma forte razāo para nāo comparecerem a atividades fora de casa. Portanto, para se criar um encontro agradável com elas, o planejamento deve levar em conta as limitaçōes previsíveis que a idade acarreta.

\section{PUBLICIDADE}

A publicidade é uma comunicaçāo impessoal, freqüentemente pensada como o primeiro passo do marketing, devido à sua 
maior visibilidade para o público ${ }^{29}$. Ela tende a receber a primeira atenção das pessoas interessadas em assimilar uma postura de marketing, sendo isto constatado no mundo das artes, visto que a promoção aparece em nível proeminente no marketing das organizações de artes mais sofisticadas ${ }^{30}$.

Uma comunicação eficaz realça duas prescrições associadas: deve ser, não só persuasiva o suficiente para superar a ignorância e $a$ inércia, como também não ser ambígua para se ajustar bem ao segmento-alvo. A comunicação em artes constitui por si só uma tarefa complexa porque seus produtos, muitas vezes indescritíveis, dificultam o processo de se comunicar com os mais velhos. Seguem, então, as seguintes diretrizes.

\section{Considerar dimensões pertinentes aos consumidores mais velhos para se comunicar eficazmente com eles}

A principal decisão de promoção é a seleção dos meios de comunicação. Os consumidores de idade apresentam um padrão de consumo de meios de comunicação diferente dos jovens, notoriamente quanto ao maior tempo que dedicam à televisão e aos jornais. Eles apreendem mais dos meios de comunicação impressos porque lhes permitem seguir um ritmo próprio de processamento de informação, compensando a deficiência no sistema nervoso central que ocorre com o envelhecimento. Há, porém, mais aspectos do que a simples seleção dos meios de comunicação ${ }^{31}$. Pessoas de idade, por exemplo, valorizam o tamanho da impressão maior do que o tipo de dez pontos na mídia impressa; sentem menos impacto das cores que puxam para o verde-azul-violeta no fim do espectro, por não serem cores facilmente discriminadas, que se misturam em sua percepção; desgostam de papel lustroso em folhetos, boletins ou cartazes porque as dificuldades de adaptação ao brilho acompanham a diminuição da visão; preferem uma ênfase nas figuras, dado que recordam-se mais de figuras do que de palavras. Em anúncios orais, eles podem preferir porta-vozes masculinos em virtude de perceberem melhor os tons graves do que os agudos e aprovam a minimizaçāo da música de fundo ou ruídos, já que o envelhecimento torna mais difícil a discriminação entre sons próximos e distantes ${ }^{32}$.

Pesquisas demonstram que pessoas mais velhas desgostam de propagandas dirigidas especificamente a elas ${ }^{33}$, pois, geralmente, sentem-se mais jovens do que a sua idade cronológica, e não se identificam com esse tipo de anúncio. Além disso, é desnecessário lembrá-las de que estão mais velhas. A propaganda sutil de características altamente desejadas pelo segmento mais velho, tais como horários convenientes, freqüência em grupo, seleção de assentos, atividades antes do evento, disponibilidade de transporte, tem mais capacidade de atrair sua atenção. Portanto, apesar de ainda se ter muito a aprender, vale ser cuidadoso com a representação de pessoas mais velhas em anúncios. Tendo em vista que tanto os jovens quanto os idosos consomem trabalhos de artes, sugere-se acompanhar os executivos de publicidade que recomendam a representação de figuras de pessoas mais velhas somente em casos em que não haja sobreposição de segmentos ${ }^{34}$.

\section{Fornecer mais informações básicas para} os consumidores de idade do que para os jovens

Consumidores mais velhos costumam ser menos informados do que os mais jovens, devido à maior dificuldade em adquirir informações e à redução das fontes pessoais de informação, conseqüência da aposentadoria, morte de cônjuge e saída dos filhos de casa ${ }^{35}$. Pode lhes faltar acesso às informações simples: saber a localização e o modus operandi de um evento artístico, o que seria impensável para os clientes mais novos. Em geral, os consumidores de idade dependem mais do que os outros do responsável pelo evento como fonte de informação.

Eles podem também não ter acesso $a$ informações devido às dificuldades em lidar com as complexidades do mundo das artes. Espetáculos artísticos constituem essencialmente serviços que já têm, por sua própria natureza, problemas inerentes de comunicação ${ }^{36}$. Além disso, muitos eventos artísticos, especialmente os menos importantes, exigem a ida até o local para se obter informações. E pessoas mais velhas
29. SCHEWE, Charles D. Marketing: principles and strategies, New York: Random House, 1987

30. DiMAggiO, Paul J. Op. cit. 31. SCHEWE, Charles D. Op. cit.

32. SCHEWE, Charles D. Effective communication with our aging population, Business Horizons, v. 32 , n. 1 , Jan.-Feb. 1989, p. 251-57.

33. VISVABHARATHY, Ganeson, RINK, David R. The elderly: neglected business opportunities, Journal of Consumer Marketing, v. 1, n. 4, 1984, p. 34-46.

34. GRECO, Alan J. Representation of the elderly in advertising: crisis or incompetence? Journal of Consumer Marketing, v. 6, n. 1, Winter 1989, p.37-44.

35. PHILLIPS, Lynn W., STERNTHAL, Brian. Age differences in information processing: a perspective on the aged consumer, Journal of Marketing Research, 14 Nov. 1977, p. 444-57.

36. ZEITHAML, Valerie A. How consumers evaluation processes differ between goods and services, Services Marketing, Englewoods Cliffs: N.J. Prentice Hall, Inc., 1984, p. 191-98. 
37. WINNER, Ellen. Invented worlds: the psychology of arts, Cambridge, Mass.: Harvard University Press, 1982

38. SCHIFFMAN, Leo G. Sources of information for the elderly, Journal of Advertising Research, 11 Dct. 1971, p. 33-7.

\section{O segmento bastante} viável de consumidores mais velhos não tem estado na vanguarda do alvo das
organizaçōes de artes.

com problemas de mobilidade vêem-se impedidas de reunir tais informações.

\section{IDENTIFICANDO ATITUDES, PREFERÊNCIA E SATISFAÇĀO}

A atitude positiva precede a predisposição para a ação, a preferência manifesta a capacidade de ordenar produtos diferentes e a satisfação significa uma percepção igual ou superior à esperada. Para captar estes fatores é necessário uma pesquisa de marketing.

A pesquisa de marketing com consumidores mais velhos enfrenta duas questōes difíceis: acomodar as necessidades físicas e cognitivas peculiares ao envelhecimento e perguntar sobre os produtos de artes, cuja apreciação provém de um efeito global, por meio de atributos decompostos de um todo. Portanto, sugerem-se as seguintes diretrizes.

Investigar com mais profundidade e paciência ao tentar identificar preferências

Isto é uma tarefa complicada. Por si só, declarar preferências por arte nāo é simples. Por se diferenciar em diversos e, muitas vezes, complexos aspectos, os trabalhos de artes levantam questōes quanto à determinação não-ambígua da base utilizada para a declaração de preferências ${ }^{37}$. Produtos de arte oferecem menos alternativas para a comparação e a aprendizagem, e, conseqüentemente, para declaraçōes inequívocas de preferências. Ademais, no caso das artes cênicas, a aprendizagem e a avaliaçāo antes da compra são excluídas, à medida que os aspectos relevantes são somente revelados durante o consumo através da experiência. Como tal, isso constitui um domínio complexo, e consumidores de idade, por manifestarem difi- culdades em lidar com complexidades, exigem mais paciência.

Deve-se dar mais atenção às técnicas qualitativas do que às quantitativas. Instrumentos quantitativos e questionários utilizados para a compreensẫo dos consumidores mais jovens podem ser inadequados para a dos mais velhos. Os pesquisadores de marketing sabem que as respostas (não necessariamente exatas) podem ser dadas simplesmente porque perguntas foram feitas. Este pode ser o caso do desejo de agradar, comum em pessoas mais velhas. A sua heterogeneidade também é uma razão que favorece os estudos qualitativos para identificar preferências. Entrevistadores e mediadores especialmente treinados podem ser necessários para fazer conexōes próprias entre dimensōes relacionadas à idade e à coleta, análise e interpretação de dados.

\section{Sondar um benefício significativo e específico com relação a dimensões inovadoras}

Consumidores mais velhos têm uma menor probabilidade de adotar inovações, sendo os últimos a fazê-la. Em virtude do declínio das suas capacidades físicas e mentais, eles se tornam mais cautelosos ao tomar decisões, porque a probabilidade de erro é maior. Entretanto, desde que identifiquem um benefício específico e significante, tornam-se mais propensos a experimentar um produto novo ${ }^{38}$.

O principal objetivo de pesquisa é, pois, identificar um benefício significante que estimule o segmento a consumir inovaçōes. Apesar de trabalhosa, essa tarefa pode ser, às vezes, bem-sucedida, como por exemplo, seis mil pessoas de mais idade nos EUA se tornaram viciadas em computadores, quando thes foi apresentado o benefício de se manter contato on line com outras pessoas de sua idade, evento proporcionado pela SeniorNet Network Cornputing. Por outro lado, a identificação de benefícios impróprios ou irrelevantes pode aumentar a consciência do risco e desencadear posturas defensivas. Esse erro de marketing pode levar a estigmas folclóricos, tais como consumidores mais velhos exigindo outra apresentaçāo do Ballet Quebra-Nozes, em vez de arriscar algo novo ou diferente. 
Estimular os consumidores mais velhos a verbalizar suas impressóes após o consumo

Devido à menor iniciativa e não à menor insatisfação, os consumidores mais velhos reclamam menos do que os mais novos $^{39}$. Ademais, têm menos oportunidades de conversar sobre um produto, tendendo a confiar em suas próprias experiências para informação e decisão ${ }^{40}$. Por causa disso, eles se tornam mais vulneráveis às informações fornecidas pelas próprias organizações de artes e tendem a focalizar sua desaprovaçāo no fornecedor. Por isso, quando insatisfeitos, poucos reclamarão; de modo que o julgamento das queixas podem enganar as organizações de artes ao avaliar os seus esforços.

\section{DOS BENEFÍCIOS PARA O CONSUMIDOR ATÉ A CRIAÇÃO ARTÍSTICA}

O sucesso artístico pode ser visto como a realização das intenções dos artistas no público-alvo ${ }^{41}$.

Na pesquisa sobre a natureza das respostas a um estímulo estético, descobriuse que as atitudes e preferências que circundam uma obra de arte variam entre os consumidores de arte e que as diferenças são devidas a vários fatores, entre eles, a idade $^{42}$. Mudanças e perdas no prazer estético ocorrem porque as reações aos estímulos são afetadas pelo envelhecimento, como resultantes de perdas na visão e audição - sentidos intimamente associados às respostas apreciativas. Tendo em vista essas questóes, apresentamos, a seguir algumas diretrizes.

\section{Incorporar características para} compensar as perdas associadas ao envelhecimento

O envelhecimento afeta a natureza das respostas apreciativas às obras de arte. Os pesquisadores do marketing de artes distinguem dois tipos de respostas apreciativas: experiências hedônicas e emocionais ${ }^{43}$ ou, da mesma maneira, valores hedônicos ou experiências profundas ${ }^{44}$. Essas respostas foram imaginadas como posiçóes polares ao longo de um continuum, indo da simples satisfação ou prazer a respostas emocionais mais profundas, com a com- preensão explícita de que valores utilitários misturam-se aos valores estéticos nas respostas dos consumidores. Respostas emocionais ou experiências profundas são associadas ao surgimento e à busca de sensaçóes, que, por sua vez, diminuem com a idade ${ }^{45}$. Portanto, o aspecto mais hedônico e utilitário da oferta de artes serve como fonte para contrabalançar as perdas decorrentes do envelhecimento.

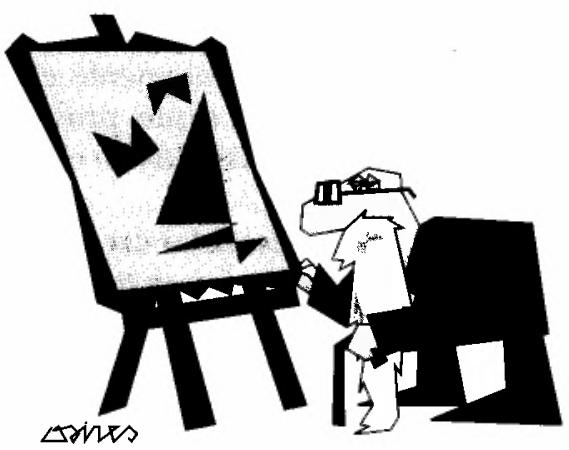

Objetividade e simplicidade, por exemplo, compensam duas dificuldades: processar um maior número de informaçôes e separar a informação relevante das irrelevantes ou dispersoras. Um ritmo mais lento permite uma melhor assimilação e abre uma oportunidade para digerir a informação, cada qual no seu ritmo próprio. Tons mais graves são mais bem recebidos do que tons agudos, e podem ser compensados pelo uso de vozes masculinas, como já foi mencionado. Mais luz se torna necessária para perceber formas. As cores vermelho e amarelo refletem mais luz, por isso são preferíveis ao azul e verde. Portanto, se a intençậo dos artistas inclui um público-alvo que não mais possui os poderes plenos dos sentidos, parece lógico que eles façam esforços para compensar as perdas que dificultam uma resposta plena de percepção estética.

\section{Produzir eventos específicos para a iniciação}

Isso é feito para o público infantil, no entanto, aparentemente não tem sido feito para o mais velho. Quando se enfoca a formação de atitudes para as artes, é provável que se descubra que as atitudes favoráveis se identificam com a familiaridade com as artes na infância ${ }^{46}$. Os decisores do marketing sabem, no entanto, que o comportamento pode preceder uma atitude, $o$ que faz da freqüência às artes um instrumento de formação de atitude ${ }^{47}$.

Eventos de iniciação são uma questão
39. BERNHARDT, Kenneth $L$. Consumer problems and complaint actions of older Americans: a national view, Journal of Retailing, v. 57, Fall 1981 p. 107-23.

40. SCHIFFMAN, Leo G. Op. cit

41. HOLBROOK, Morris B., ZIRLIN, Robert B. Op. cit.

42. WINNER, Ellen. Op. cit.

43. WOOD, Walter A. Op. cit

44. HOLBROOK, Morris B. ZIRLIN, Robert B. Op. cit.

45. ZUCKERMAN, Marvin. Sensation seeking: beyond the optimal level of arousal, Hillsdale, New Jersey: Lawrence Erlbaum Associates, 1979.

46. BAMOSSY, Gary. Aesthetic judgment and arts patronage of adolescents. In: Advances in nonprofit marketing, v. 1 ., 1985, p. 161-206; Greenwich, CT: JAI Press, 1985.

47. Idem, ibidem. 
48. WOOD, Walter A. Op. cit., HIRSCHMAN, Elizabeth, C. Op. cit.

49. STEINBERG, Margery et al. Op. cit.

50. SCHEWE, Charles D. Op. cit. menos sensível à educação do que às artes. Pessoas mais velhas elogiam esforços feitos sob medida e esperam demonstrações de interesse sincero. Com isso, repetições de comportamentos serão em grande parte atingidos através de eventos de iniciação, que servirão àqueles que foram insuficientemente expostos a eventos artísticos, e que provavelmente nāo seriam conquistados de outra maneira.

\section{Acrescentar características ao produto de artes para torná-lo competitivo frente a outras formas de lazer}

Os decisores do marketing das artes vêem a presença num evento de artes como uma experiência que não pode ser substituída por nenhum outro produto ou serviço ${ }^{48}$. Contudo, pesquisas sobre atividades de lazer incluem, muitas vezes, eventos de artes no grupo para uso alternativo do tempo disponível. Misturar eventos de artes com atividades esportivas e turísticas revela a existência de benefícios comuns e competitivos dentro do mesmo grupo. Em relação às pessoas que não freqüentam esse tipo de evento, descobriu-se que, apesar da diversidade de benefícios em atividades de lazer diferentes, existem benefícios fundamentais nas artes $^{49}$.

Em termos de estratégia de marketing, isto requer um posicionamento competitivo com os eventos nāo-artísticos, ou seja, o de colocar um produto de arte na mente do consumidor de forma que ele possa compará-lo vantajosamente com atividades esportivas ou recreativas. Apesar de o posicionamento poder ser realizado através de esquemas publicitários, uma abordagem mais eficaz exige a inclusão dos benefícios na fase de concepção do produto. Para isto, três abordagens de posicionamento ${ }^{50}$ parecem ser mais atraentes. Primeiro, os produtos de artes podem ser posicionados num sentido de um propósito; nesses casos oferece-se aos adultos mais velhos uma oportunidade para aprender, sentir-se útil e crescer como pessoa. Diversos programas de viagem bem-sucedidos para os mais velhos são concebidos, desenvolvidos e implementados, tendo a aprendizagem como conceito fundamental, o que causa impacto na seleção de lugares, meios de transporte, duração e gui- as, entre outros. Segundo, pode-se empregar o posicionamento sobre a experiência; à medida que pessoas de mais idade preferem experiências a "coisas", os eventos artísticos podem ser colocados como tal. Para competir nessa abordagem, é preciso conceber a experiência não como um apêndice, mas como um conceito central; muitos eventos esportivos e de lazer oferecem oportunidades para "viver" $\mathrm{e}$ "encontrar", em vez de experiências associadas a "ver" e "ouvir". Finalmente, o posicionamento pode ser baseado na nostalgia, fazendo associações aos "velhos tempos". O público de mais idade, por exemplo, aprecia musicais e shows que os remetem a momentos alegres de sua juventude. Para ser competitivo, o posicionamento na nostalgia deve ser criativo e associar aspectos que impliquem a seleção de artistas, intérpretes, músicas, estilos, scripts, locais e muitos outros. Em suma, o produto de arte pode ser bem posicionado na mente dos consumidores se for competitivo, tendo por base o desenvolvimento de esforços de marketing que incorporem tanto as peculiaridades do segmento quanto os benefícios encontrados em outras atividades de lazer.

\section{CONCLUSÃO}

Os decisores do marketing das artes têm sido lentos em empregar os princípios básicos do marketing moderno, notoriamente quanto à valorização do consumidor. $\mathrm{O}$ segmento bastante viável de consumidores mais velhos não tem estado na vanguarda do alvo das organizações de artes, que, no entanto, devido a razões sociais e econômicas, deveria estar. A essência do sucesso em marketing começa com uma sólida compreensão dos desejos, preferências e peculiaridades do público-alvo. Este artigo se baseou em pesquisas para fornecer um conjunto de diretrizes, que, se seguidas, devem proporcionar maiores níveis de satisfação para as pessoas de mais idade, com relação ao consumo de produtos artísticos e, em troca, levar os decisores do marketing das artes a obter maior sucesso em seus empreendimentos.

\section{4}

